Case Report

\title{
Spontaneous Detorsion of Sigmoid Volvulus in a patient with Nineteen-Volvulus episode history: A rare outcome of an extremely rare clinical entity
}

\author{
Sabri Selcuk Atamanalp ${ }^{1}$, Esra Disci², \\ Cansu Tatar Atamanalp ${ }^{3}$, Refik Selim Atamanalp 4
}

\begin{abstract}
Sigmoid volvulus (SV) recurrence more than 10 times is an extremely rare clinical entity and spontaneous detorsion is a rare outcome of SV. In this paper, we report a case with 19 previous SV attacks, in last of which spontaneous detorsion occurred. Such a multiple-episode history as well as an unexpected recovery was unique in a 1,036-case clinical profession of Ataturk University with SV over a 54.5-year period.
\end{abstract}

KEYWORDS: Sigmoid volvulus, Recurrence, Spontaneous detorsion.

doi: https://doi.org/10.12669/pjms.37.7.4703

How to cite this:

Atamanalp SS, Disci E, Tatar Atamanalp C, Atamanalp RS. Spontaneous Detorsion of Sigmoid Volvulus in a patient with NineteenVolvulus episode history: A rare outcome of an extremely rare clinical entity. Pak J Med Sci. 2021;37(7):2029-2031. doi: https://doi.org/10.12669/pjms.37.7.4703

This is an Open Access article distributed under the terms of the Creative Commons Attribution License (http://creativecommons.org/licenses/by/3.0), which permits unrestricted use, distribution, and reproduction in any medium, provided the original work is properly cited.

\section{INTRODUCTION}

Sigmoid volvulus (SV), a closed-loop colonic obstruction, is a rare disease worldwide, while it is relatively common in some Asian, African,

1. Prof. Sabri Selcuk Atamanalp, MD.

2. Esra Disci, MD.

Assistant Professor,

3. Cansu Tatar Atamanalp, MD.

Assistant,

Department of Pediatrics,

Haseki Education and Research Hospital,

Istanbul, Turkey.

4. Refik Selim Atamanalp, MD.

Assistant,

Department of Pathology,

Prof. Dr. Cemil Tascioglu City Hospital,

Istanbul, Turkey.

1, 2: Department of General Surgery,

Faculty of Medicine,

Ataturk University,

Erzurum, Turkey.

Correspondence:

Prof. Sabri Selcuk Atamanalp, MD.

Department of General Surgery,

Faculty of Medicine,

Ataturk University, 25040,

Erzurum, Turkey.

E-mail: ssa@atauni.edu.tr

* Received for Publication:

May 11, 2021

* Accepted for Publication:

July 5, 2021
South American, and Eastern European countries. ${ }^{1}$ Although the recurrence of SV is not a mystery, multiple recurrence attacks, particularly more than 10 times, are extremely rare with a few cases reported to date. ${ }^{2}$ Spontaneous detorsion is an unusual outcome of SV, which is seen in fewer than $2 \%$ of SV cases. ${ }^{3}$ We report herein a case of a 72-year-old man with 19-recurrence attack history, the last of which healed spontaneously. We encountered both of these clinical characteristics for the first time in a 1,036-case clinical experience with SV over a 54.5-year period (from June 1966 to January 2021) in Ataturk University.

\section{CASE REPORT}

A 72-year-old man presented with abdominal pain, distention, and obstipation for 12 hours. He was previously diagnosed with coarctation of aorta and coronary disease. In anamnesis, a history of 19 volvulus attacks was present. All SV episodes including the first one in childhood, had been decompressed endoscopically. Physical examination revealed asymmetrical abdominal distention more prominent in left upper quadrant (Fig.1a), abdominal tenderness, hyperkinetic bowel sound, and an empty rectum. Abdominal 


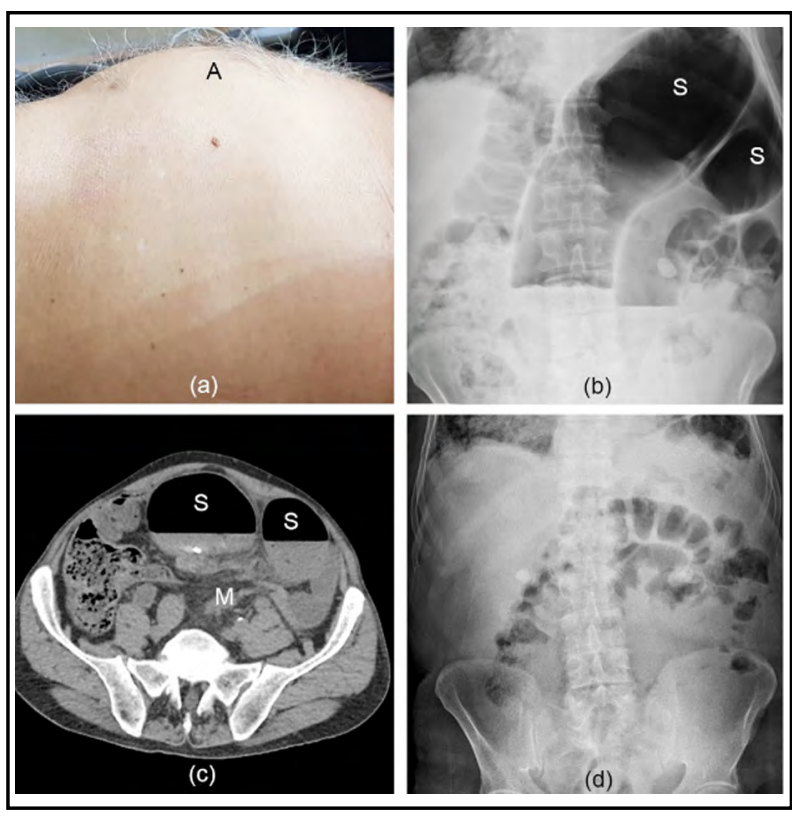

Fig.1: (a) Clinical appearance (A: asymmetrically distended abdomen), (b) Plain abdominal X-ray image (S: twisted sigmoid colon segments forming coffee bean sign), (c) Axial abdominal CT image (S: dilated sigmoid colon, M: mesenteric whirl sign), (d) Control plain abdominal X-ray image.

X-ray radiography demonstrated dilated sigmoid colon segments forming coffee bean sign (Fig.1b). Abdominal CT scan presented dilated sigmoid colon segments in addition to mesenteric whirl sign (Fig.1c). According to the clinical and radiological findings, SV with nongangrenous bowel was diagnosed. Following resuscitation, an endoscopic detorsion was planned. During the preparation period, the patient defecated normal-appearing stool together with abundant degassification. A follow-up examination revealed a relaxed abdomen with minimal tenderness. There was no abnormal finding in the control abdominal X-ray radiography (Fig.1d). Due to the poor general condition of the patient (American Society of Anesthesiologists-ASA score 4) arising from serious comorbidities, an elective surgery was not suggested, and he didn't approve percutaneous endoscopic colopexy (PEC). The patient was discharged after a 24-hour observation.

\section{DISCUSSION}

SV tends to recur in about one fourth of all cases. The recurrence rate principally depends on the treatment method, and it is more common in patients treated with endoscopic or surgical detorsion alone. Similarly, pediatric SV is considerably disposed to recurrence. ${ }^{4}$ On the other hand, due to the elective surgical treatment of some selected patients in addition to the loss of some others during the observation period, multiple recurrence attacks more than 10 times are extremely rare with a few cases reported to date. ${ }^{2}$ On SV, we have a 1,036-case experience, which is the largest single-center SV series in the world. ${ }^{5}$ Of our 935 patients, whose records were available, $242(25.9 \%)$ presented a previous volvulus episode with a mean 1.4 times. In our series, 206 patients had a single attack, 31 patients had 2-5 attacks, two patients had 6-10 attacks, and three patients had 11 or more attacks, while the presented case was the first patient with 19 attacks.

The sigmoid colon occasionally twists and untwists, and these are accepted physiologically. Torsions less than $180^{\circ}$ are generally asymptomatic and result in spontaneous untwisting. If the torsion exceeds $180^{\circ}$, intestinal passage is blocked and complications including bowel ischemia, necrosis, and perforation may occur. ${ }^{6,7}$ In such patients, spontaneous detorsion is difficult or even impossible due to gas generation in the closed loop and it is expected in fewer than $2 \%$ of the cases. ${ }^{1}$ The presented case was the first patient who recovered spontaneously following the diagnosis of SV during the hospitalization period.

It is clear that every volvulus attack carries some risks of mortality and morbidity. ${ }^{5}$ However, in our opinion and experience, this disadvantage may provide some other interesting advantages in patients with multiple volvulus attacks. Firstly, due to their previous clinical experiences, such patients generally get used to the clinical presentation of SV. Thus, they may visit to hospital without loss of time. Secondly, SV diagnosis is frequently made by patients at admission, which may provide early and correct diagnosis. Finally, repetitive attacks facilitate not only twisting but also untwisting of the sigmoid colon, which may lead to spontaneous detorsion of SV.

Regarding the treatment options in patients with poor general conditions, like the presented case, in our opinion and experience, observation is generally preferred by both physicians and the patients to avoid unintended consequences. Neither emergency nor elective surgical sigmoid colectomy is thought as the optimal choice due to their poor prognosis, which consists of 10 $30 \%$ of mortality and $20-40 \%$ of morbidity rates. ${ }^{5}$ Instead, emergency or preferably elective PEC 
may be a proper option. Despite the limited experience on PEC treatment in SV including fewer than 100 cases reported to date, it is a hope in selected patients. ${ }^{8,9}$ PEC doesn't require general anesthesia and may be applied under endoscopic premedication together with local anesthesia, and may demonstrate acceptable results with 5-13\% of mortality and $13-18 \%$ of morbidity rates. ${ }^{10}$

\section{Conflict of Interest: None.}

Grant Support \& Financial Disclosures: None.

\section{REFERENCES}

1. Bauman ZM, Evans CH. Volvulus. Surg Clin North Am. 2018;98(5):973-993. doi: 10.1016/J.suc.2018.06.005

2. Web of Science. Sigmoid volvulus. [Accessed May 2021]. http://apps.webofknowledge.com/Search.do? product $=$ WOS $\& S I D=E 6 a 4 O w 4 s s d m 18$ NSOOoZ\&sear ch_mode $=$ GeneralSearch $\&$ prID $=6 f 7 f 884 \mathrm{e}-\mathrm{a} 95 \mathrm{~b}-4854-8 \mathrm{a} 5 \mathrm{c}-$ 6c439d41b6a6.

3. Ballantyne GH, Brandner MD, Beart RW, Ilstrup DM. Volvulus of the colon. Incidence and mortality. Ann Surg 1985;202(1):83-92. doi: 10.1097/00000658-198507000-00014

4. Atamanalp SS. Sigmoid volvulus: avoiding recurrence. Tech Coloproctol. 2019;23(4):405-406. doi: 10.1007/s10151019-01984-1

5. Atamanalp SS. Sigmoid volvulus: An update for Atamanalp classification. Pak J Med Sci. 2020;36(5):1137-1139. doi: $10.12669 /$ pjms.36.5.2320
6. Perrot L, Fohlen A, Alves A, Lubrano J. Management of the colonic volvulus in 2016. J Visc Surg. 2016;153(3):183-192. doi: 10.1016/j.jviscsurg.2016.03.006

7. Raveenthiran V, Madiba TE, Atamanalp SS, De U. Volvulus of the sigmoid colon. Colorectal Dis. 2010;12(7):E1-E17. doi: 10.1111/j.1463-1318.2010.02262.x

8. Imakita T, Suzuki Y, Ohdaira H, Urashima M. Colonoscopy-assisted percutaneous sigmoidopexy: a novel, simple, safe, and effective treatment for inoperable sigmoid volvulus. Gastrointest Endosc. 2019;90(3):514-520. doi: 10.1016/j. gie.2019.04.246

9. Jackson S, Hamed MO, Shabbir J. Management of sigmoid volvulus using percutaneous endoscopic colostomy. Ann R Coll Surg Engl. 2020;102(9):654-662. doi: 10.1308/ rcsann.2020.0162

10. Atamanalp SS. Expert commentary on the diagnosis and management of sigmoid volvulus. Dis Colon Rectum. 2021;64(4):378-379. doi: 10.1097/DCR.0000000000001948

\section{Authors Contribution:}

SSA: Data collection, manuscript writing. ED: Data collection, revision of the final draft.

CTA: Revision of the final draft.

RSA: Revision of the final draft.

SSA: Is responsible for responsible and accountable for the accuracy or integrity of the work. 